\title{
Hydrologic response of an alpine watershed: Application of a meteorological wireless sensor network to understand streamflow generation
}

\author{
S. Simoni, ${ }^{1,2,3,4}$ S. Padoan, ${ }^{1,5}$ D. F. Nadeau, ${ }^{1}$ M. Diebold, ${ }^{1}$ A. Porporato, ${ }^{2}$ G. Barrenetxea, ${ }^{3}$ \\ F. Ingelrest, ${ }^{3}$ M. Vetterli, ${ }^{3}$ and M. B. Parlange ${ }^{1}$
}

Received 30 March 2011; revised 23 August 2011; accepted 7 September 2011; published 22 October 2011.

[1] A field measurement campaign was conducted from June to October 2009 in a $20 \mathrm{~km}^{2}$ catchment of the Swiss Alps with a wireless network of 12 weather stations and river discharge monitoring. The objective was to investigate the spatial variability of meteorological forcing and to assess its impact on streamflow generation. The analysis of the runoff dynamics highlighted the important contribution of snowmelt from spring to early summer. During the entire experimental period, the streamflow discharge was dominated by base flow contributions with temporal variations due to occasional rainfallrunoff events and a regular contribution from glacier melt. Given the importance of snow and ice melt runoff in this catchment, patterns of near-surface air temperatures were studied in detail. Statistical data analyses revealed that meteorological variables inside the watershed exhibit spatial variability. Air temperatures were influenced by topographic effects such as slope, aspect, and elevation. Rainfall was found to be spatially variable inside the catchment. The impact of this variability on streamflow generation was assessed using a lumped degree-day model. Despite the variability within the watershed, the streamflow discharge could be described using the lumped model. The novelty of this work mainly consists in quantifying spatial variability for a small watershed and showing to which extent this is important. When the focus is on aggregated outputs, such as streamflow discharge, average values of meteorological forcing can be adequately used. On the contrary, when the focus is on distributed fields such as evaporation or soil moisture, their estimate can benefit from distributed measurements.

Citation: Simoni, S., S. Padoan, D. F. Nadeau, M. Diebold, A. Porporato, G. Barrenetxea, F. Ingelrest, M. Vetterli, and M. B. Parlange (2011), Hydrologic response of an alpine watershed: Application of a meteorological wireless sensor network to understand streamflow generation, Water Resour. Res., 47, W10524, doi:10.1029/2011WR010730.

\section{Introduction}

[2] The runoff generation of many elevated mountainous basins in the Alps is dominated by snow and glacier melt during the peak stream runoff period. Changes in the timing and magnitude of mountainous streamflows due to modifications in the snowfall regime expected as a result of climate change [Christoph, 2008]. For instance, increasing air temperatures should lead to an earlier spring snowmelt and a reduced snow accumulation in winter [Barnett et al., 2005]. These changes will have important consequences at the global scale, especially since a sixth of the world's pop-

\footnotetext{
${ }^{1}$ School of Architecture, Civil and Environmental Engineering, École Polytechnique Fédérale de Lausanne, Lausanne, Switzerland.

${ }^{2}$ Department of Civil and Environmental Engineering, Duke University, Durham, North Carolina, USA.

${ }^{3}$ School of Computer and Communication Sciences, École Polytechnique Fédérale de Lausanne, Lausanne, Switzerland.

${ }^{4}$ Now at Mountain-eering Srl, Bolzano, Italy.

${ }^{5}$ Dipartimento di Ingegneria dell'informazione e metodi matematici, Università degli studi di Bergamo, Dalmine, Italy.
}

Copyright 2011 by the American Geophysical Union. 0043-1397/11/2011WR010730 ulation relies on snow or ice melt for their water supply [Barnett et al., 2005]. Schaefli et al. [2007] have also shown that a warming climate would result in a reduced performance of hydropower production in regions like the Swiss Alps, where large reservoirs are filled annually with glacier and snow melt.

[3] For water management purposes, it is critical to be able to monitor and model the hydrology of ice- and snowmelt-dominated alpine catchments [Nolin et al., 2010]. Predicting melting rates is a challenging task. For instance, significant snow drift over the course of the winter results in strong heterogeneities in the depth of the snowpack and in the snow-water equivalent by the end of the melting season [Luce et al., 1998; Anderton et al., 2004; DeBeer and Pomeroy, 2010]. The snowpack is also typically deeper at higher altitudes [Garen and Marks, 2001; Anderson, 2006; Bales et al., 2006], which are often less well instrumented than lower portions of the watershed [Robeson, 1995].

[4] The available energy for snowmelt depends on several factors, including the local radiation budget, which is influenced by the slope and the aspect [Cazorzi and DallaFontana, 1996], the local turbulent fluxes of sensible and latent heat, and warm-air advection [Sicart et al., 2008]. 
The turbulent fluxes and the advection are associated with the complex circulations that form in the atmospheric boundary layer over mountainous terrain. For instance, on a clear-sky day in summertime, winds form along the slopes of a mountain valley as a result of temperature gradients between the air over the valley sidewalls and at the center of the valley (D. F. Nadeau et al., Flow during the evening transition over steep alpine slopes, submitted to Quarterly Journal of the Royal Meteorological Society, 2011). Several studies have focused on these mountainous flows and their implications in hydrology [e.g., Lundquist et al., 2010; Shea and Moore, 2010]. A complete summary of their fundamental features is given by Whiteman [2000].

[5] Once the primary melting season is over, the runoff is largely due to some combination of base flow and rainfall-runoff events [Brutsaert and Nieber, 1977; Szilagyi and Parlange, 1999]. In alpine catchments, the precipitation is highly variable in space and time [see Obled et al., 1994; Smith et al., 2000]. In summertime, for instance, heavy thunderstorms can locally deliver significant amounts of water while lasting only a few tens of minutes [Redaño and Lorente, 1993]. The complex geological and morphological structures of the watershed will then accelerate or delay the response, introducing significant nonlinearities in the rainfall-runoff transformation [Rinaldo et al., 1991; Stagnitti et al., 1992; Szilagyi and Parlange, 1999; Grayson et al., 2002; Porporato and Ridolfi, 2003]. Other nonlinearities are caused by the strong correlations between the antecedent soil moisture and runoff coefficients; intensive convective rainfall events will often generate streamflow only if the soil is sufficiently saturated [Coles et al., 1997; Bronstert and Bardossy, 1999; Tromp-van Meerveld and McDonnell, 2006].

[6] The hydrologic monitoring of the complex processes taking place in alpine catchments is often limited to one or, at most, a few point measurements, usually at lower elevations. The lack of distributed measures remains, even today, the most difficult aspect to advance hydrologic science. Indeed, mountainous regions are typically inaccessible, and thus, the deployment and maintenance of instrumentation are difficult tasks. For hydrologic monitoring purposes, the representativeness of point measurements extrapolated to the basin scale is questioned [Klemes, 1990; Blöschl, 1991] since the terrain is usually highly variable (large range of slopes, aspects, elevations, and surface types) over several scales [Seyfried and Wilcox, 1995]. The nature of this spatial variability and the consequences for hydrologic simulation have long been discussed within the hydrologic community [Obled et al., 1994; Seyfried and Wilcox, 1995; Shah et al., 1996; Arnaud et al., 2002; Atkinson et al., 2003; Syed et al., 2003; Bales et al., 2006; Pomeroy et al., 2008; Tyler et al., 2008; Painter et al., 2009; Smith et al., 2009; Vico and Porporato, 2009; Grünewald et al., 2010; Flerchinger et al., 2010]. It is often reasoned that the smaller the catchment, the higher the temporal and spatial resolutions needed to capture hydrological processes [Smith et al., 2000; Mandapaka et al., 2009]. A large catchment is thought to act as a damping filter for input forcing and produces smoothed output; therefore, the processes can be sampled and modeled at coarser resolutions [Settin et al., 2007; Mandapaka et al., 2009]. The response time of a small watershed $\left(<100 \mathrm{~km}^{2}\right)$ is typically shorter; hence, in order to describe the output signal, higher spatiotemporal resolutions are necessary [Niemczynowicz, 1991].

[7] One new generation measuring approach to capture some of the spatial variability present inside an alpine catchment is to deploy a wireless sensor network, with multiple input measurements. Such a network for measuring meteorological inputs $(\approx 100$ stations) has been successfully deployed, perhaps for the first time, by Nadeau et al. [2009] to quantify regional sensible heat flux. Trubilowicz et al. [2009] have also used a sensor network (41 stations) to study the hydrology of a small forested catchment in western Canada. Both studies highlighted the great potential of such systems for hydrological studies, given that the networks were reliable and easy to use.

[8] The monitoring of an alpine catchment is often motivated by the need for inputs in hydrologic models used to predict the streamflow discharge or soil moisture distribution for landslide analyses [Simoni et al., 2008]. There is a wide range of modeling tools available in the hydrologic literature, from minimal lumped models to fully distributed deterministic models. While there is some debate about the capacity of distributed models to yield accurate results given the difficulty to gather the necessary input information [Grayson et al., 1992], some attempts over mountainous basins have proven to be successful [e.g., Kelleners et al., 2010].

[9] In this study, we instrumented a small $\left(\approx 20 \mathrm{~km}^{2}\right)$, previously ungauged, snowmelt-dominated alpine catchment of the Swiss Alps with a weather station network from the end of the melting season to the early fall. Water level at the catchment outlet was also measured continuously and converted to streamflow through a stage-discharge curve. The overall goal of this study is to investigate the spatial variability of meteorological forcing in an alpine watershed and its impacts on streamflow generation. To address this goal, the runoff dynamics of the watershed are first analyzed. Then a statistical analysis of air temperature and rainfall measurements collected by the distributed sensor network is performed to verify the presence of spatial variability. The impact of spatial variability on streamflow generation is then assessed using a simple lumped degree-day model in combination with distributed weather data.

\section{The 2009 Field Campaign in Val Ferret, Switzerland}

[10] A field deployment was conducted to investigate the spatial variability of meteorological forcings and to study streamflow generation in a steep alpine watershed. The campaign was initiated in May 2009 and was fully operational from June to October 2009. The experimental site (see Figure 1) was located in Val Ferret in the southwestern Swiss Alps, close to the border with Italy and France. The site is a subcatchment of the Dranse de Ferret, the main river of the region. It has a total surface of $20.5 \mathrm{~km}^{2}$ and altitudes ranging from $1775 \mathrm{~m}$ above sea level (asl) at the outlet to $3206 \mathrm{~m}$ asl along the southernmost ridge that borders Italy. The main axis of the valley runs along the Dranse de Ferret from southeast to northwest. Figure 2 characterizes the watershed morphology as to the distribution of elevation and aspect. The river stems from the small glacier des Angroniettes $\left(\approx 0.7 \mathrm{~km}^{2}\right)$, which lies at the southernmost part of the watershed. The hydrographic right 
(a)

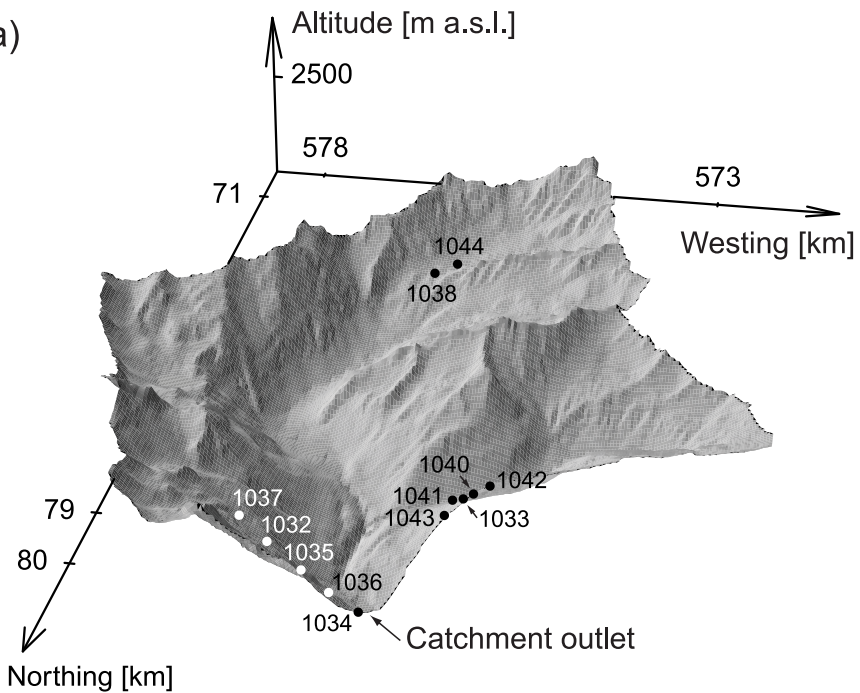

(b)

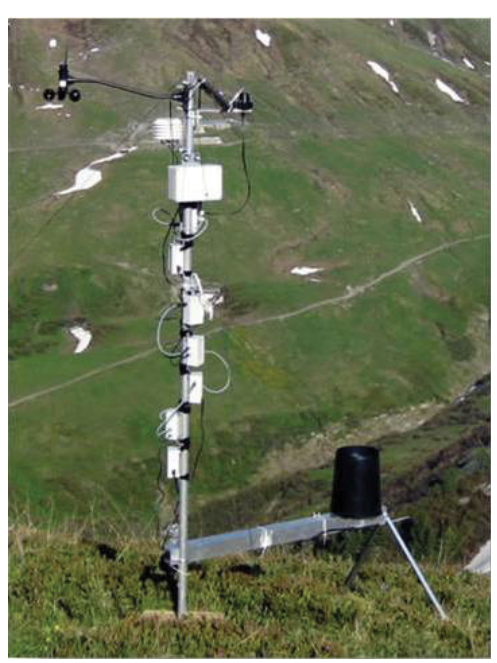

Figure 1. (a) Three-dimensional view of the study area built on a $25 \mathrm{~m}$ digital elevation model. Sensorscope stations are displayed with points and labels. Stations 1038 and 1044 are located on the glacier des Angroniettes. Details on the stations are provided in Table 3. (b) A Sensorscope station.

side of the catchment is soil mantled and characterized by mild to moderate slopes covered with meadows. On the contrary, the hydrographic left side is relatively steep, with several rocky outcrops and with the vegetation mainly consisting of grassland and sparse firs at lower elevations.

[11] The climate of the study area is characterized by a long winter where sustained snowfall usually starts in November, and extensive snow cover is typically found until the end of May. Springs are normally dry, and summers are generally mild, with variable thunderstorms and local weather events, while the fall season tends to have regular rainfalls over the entire watershed.

[12] The site was selected partly because its hydrology has not been altered by hydroelectric power plants, which is not the case for many of the alpine valleys in this part of Switzerland. Hence, there are neither dams nor pipes modifying the natural hydrology of this area, with the exception of a drinking water intake $\left(\approx 17 \mathrm{~L} \mathrm{~s}^{-1}\right)$.

[13] Most of the data were collected by a wireless network of 12 weather stations (Sensorscope [Ingelrest et al.,
2010]) distributed over both sides of the river, primarily at the northern end of the catchment. Ten of these stations (1032-1037 and 1040-1043 on Figure 1) were operational from June to mid-October. The two stations located at the southern end (1038 and 1044) collected data over the glacier des Angroniettes from September to mid-October. Each station was equipped with several meteorological sensors (precipitation, wind speed and direction, solar radiation, air temperature and humidity, and skin temperature) and soil sensors (moisture, temperature and suction). In this particular study, air temperature, rainfall, and soil moisture are used. The air temperature measurements were collected at $1.5 \mathrm{~m}$ above the surface using a Sensirion SHT75 sensor protected by a radiation shield. It is known that such temperature measurements can be susceptible to heating effects because of radiative loading [Huwald et al., 2009]. In this study we ignored these effects on our temperature measurements since we are currently undertaking new field campaigns to assess how much of an impact this can have. Rainfall was measured with a tipping bucket rain gauge (Davis Rain Collector (a)

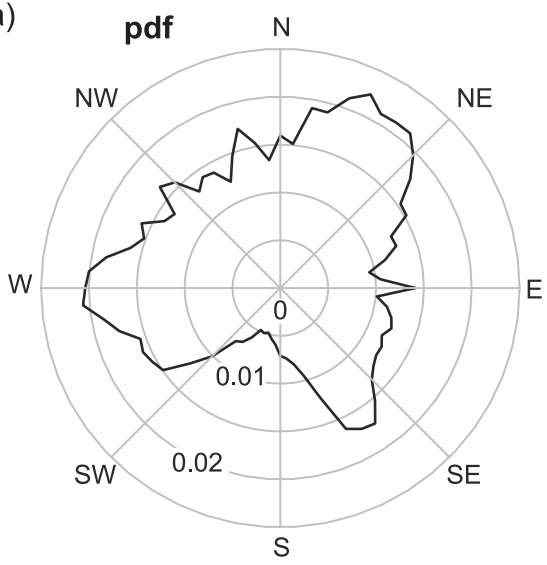

(b)

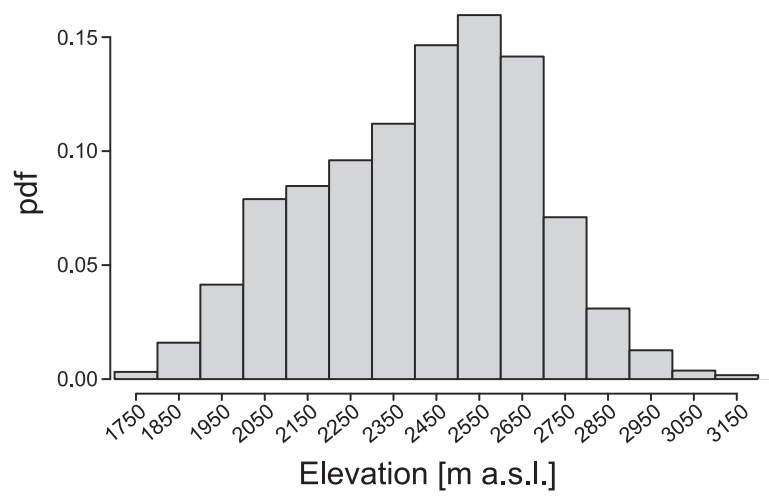

Figure 2. (a) Normalized radial histogram of aspects in the watershed. (b) Normalized histogram of elevations in the watershed. Note that pdf stands for probability density function. 
II) installed $0.4 \mathrm{~m}$ above the ground. The soil moisture data were obtained with a Decagon $\mathrm{ECH}_{2} \mathrm{O}$ EC-5 probe located $30 \mathrm{~cm}$ below the surface. The position of the soil sensors was chosen to capture the soil response to rainfall infiltration. Indeed, installing these sensors too close to the surface would cause the measurements to be biased by surface processes, such as heat exchanges between the soil and the atmosphere. All data were taken at 1 min intervals and were accessible in real time on the Internet (http://www.climaps. com). The wireless network relied on Sensorscope technology, which consists of a system of master and slave stations, where the master transmits the data collected by the slave stations to a remote server using a general packet radio service (GPRS) connection [Nadeau et al., 2009; Ingelrest et al., 2010]. Given the alpine character of the site, these stations are necessarily light, robust, and relatively easy to deploy. In the 2009 version of the wireless network, the distance between two Sensorscope stations could not exceed $400 \mathrm{~m}$ due to the rough and steep terrain (over flat terrain, distances of $2 \mathrm{~km}$ between stations were achievable). These constrains have more recently been extended. Apart from this factor, the locations of the Sensorscope stations were determined by selecting the most representative morphological features of the catchment in terms of slope, aspect, and elevation.

[14] The river water level was continuously monitored with a pressure transducer, $5 \mathrm{~min}$ sampling rate, installed at the catchment outlet (see Figure 1) from May to October 2009. The streamflow was derived via a stage-discharge relationship (see Figure 3), where discharge measurements were taken with the salt dilution method on a weekly basis. The empirical coefficients found are presented in section 3 . These coefficients are considered valid for the duration of the experiment given that there were no major episodes of sediment transport or debris flow that would have altered the geometry of the stream section (see section 3 ).

\section{Dynamics of the Streamflow Generation}

[15] By regressing the water levels and the discharge measurements, the following stage-discharge relationship was obtained:

$$
Q=1.594(h+15.557)^{2.027},
$$

where $Q$ is the discharge in $\mathrm{L} \mathrm{s}^{-1}$ and $h$ is the water level in $\mathrm{cm}$. The associated coefficient of determination is $r^{2}=0.935$.
[16] Throughout the experiment, the discharges observed varied from $7 \mathrm{~m}^{3} \mathrm{~s}^{-1}$ in mid-June to approximately $0.4 \mathrm{~m}^{3} \mathrm{~s}^{-1}$ at the end of October (Figure 3). The watershed runoff was highly dominated by snowmelt from May to mid-July. During this period, the discharges followed a clear diurnal cycle with maximum values in the late afternoon. The amplitude of the diurnal fluctuations in $Q$ decreased later in the season in response to the depleting snowpack. Indeed, in early June the watershed was almost completely covered by snow, while around mid-July only a few patches of snow remained in the shaded gullies. Toward the end of September, the discharge was around a few hundreds liters per second, with diurnal variations of some tens of liters per second.

[17] The diurnal cycle of $Q$ was highly correlated with air temperature fluctuations (Figure $4 \mathrm{~b}$ ). For instance, from 7 to 12 July, the air temperatures dropped, reducing the snowmelt and resulting in a strong decrease in streamflow magnitude (Figure 4a). The glacier melt diurnal contribution to streamflow is more obvious when the snowmelt was significantly smaller in July. The glacier melt and snowmelt signatures in the diurnal cycle of $Q$ are fundamentally different. The glacier acts as a single source of water located at the headwater of the river, resulting in a saw-tooth shape in the discharge signal. On the other hand, the snowmelt was a relatively well distributed source of water throughout the hillslopes and the channel network, resulting in a symmetric shape in the discharge signal. Note that the amplitude of the glacier signal remained quite constant throughout the season (approximately $0.2 \mathrm{~m}^{3} \mathrm{~s}^{-1}$ ). This behavior could be due to the fact that the glacier surface area did not vary significantly and that the mean daily temperature within the glacier area varied less than in other parts of the catchment.

[18] Rainfall-runoff response depends on antecedent soil moisture [Loague and Freeze, 1985; Brutsaert, 1986; Zehe et al., 2010], both in terms of magnitude and timing. Figure 4a shows responses of different magnitude and timing for similar rainfall events, such as those of 24-25 July and 24-25 August. The peak of $2.5 \mathrm{~m}^{3} \mathrm{~s}^{-1}$ on 24 July was enhanced by the nearly saturated soil prior to the rainfall (see Figure 4c). Since soil moisture was lower on 24 August, a larger amount of water could infiltrate into the soil. As a consequence, the increase in river discharge was relatively smaller and slower.

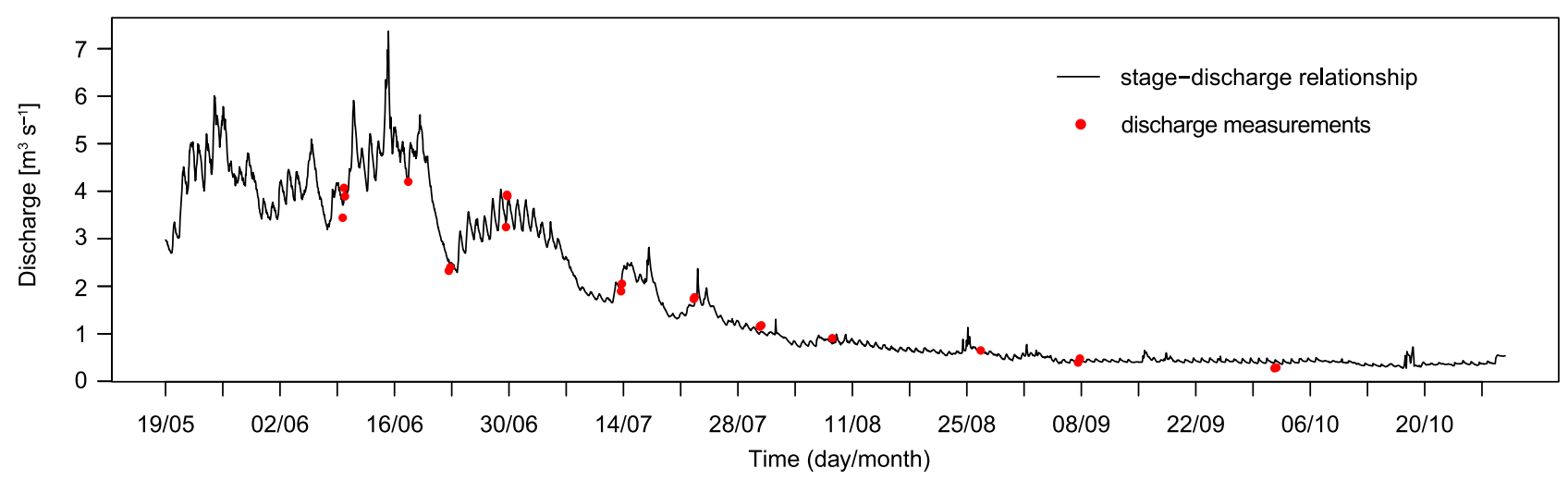

Figure 3. Time series of river flow for the study period. The black curve is obtained from the stagedischarge relationship (see section 3), and the red dots are discharge measurements obtained with the salt dilution method. 

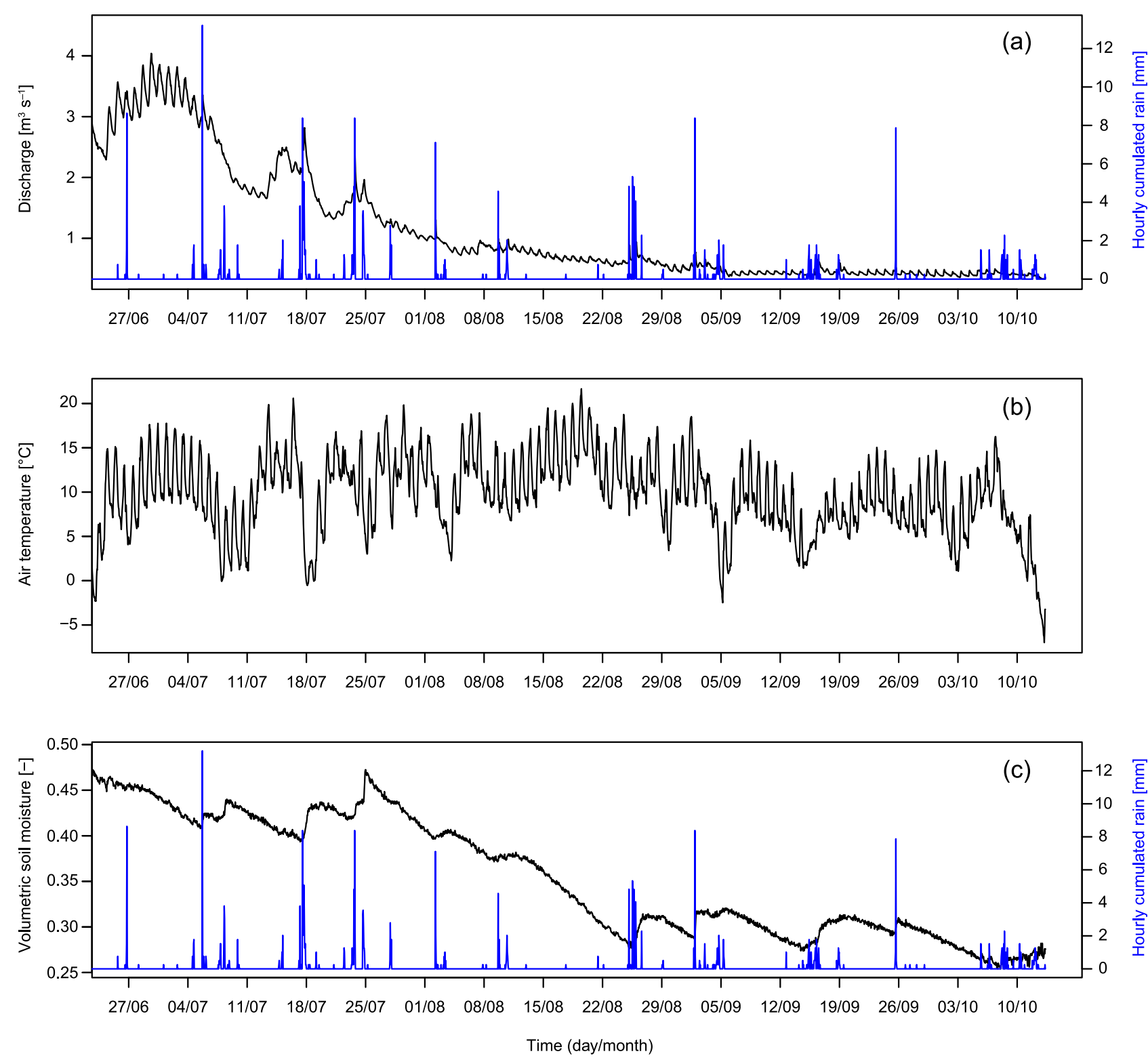

Figure 4. (a) Time series of river discharge for the study period. The black curve is obtained from the stage-discharge relationship (see (1)). Four main components are evident: snow and glacier melt, rainfall runoff, and deep drainage decay. Rainfall measurements from station 1043 are shown in blue. (b) Nearsurface air temperatures measured at station 1043. (c) Soil moisture $20 \mathrm{~cm}$ below the surface measured at station 1043. Rainfall measurements from station 1043 are shown in blue.

[19] A seasonal decreasing trend in the streamflow was also evident throughout the experimental period. This trend reflected the long-term base flow drainage [Brutsaert and Nieber, 1977]. Since we are mainly interested in the effects of spatial variability related to short and midterm processes, we do not investigate in detail the smoothing effect of base flow recession on discharge [see, e.g., Szilagyi et al., 1998].

\section{Spatial Variability of Air Temperature and Rainfall}

[20] In this section, we investigate the spatial variability of air temperature and rainfall inside the watershed by performing statistical tests and studying the existence of horizontal or vertical patterns.
[21] Air temperature and rainfall data were searched for a dependence structure across the study area. The box plots of hourly averaged air temperature and rainfall data are shown in Figure 5 for the 1 month period (mid-September to mid-October) when all the stations were operational. Clearly, air temperature is highly variable throughout the watershed, with medians ranging between $5^{\circ} \mathrm{C}$ and $10^{\circ} \mathrm{C}$ (see Figure 5a). As expected, the two stations on the glacier report colder temperatures than the others. The spatial variability of daily precipitation is also nonnegligible, as seen on Figure $5 b$.

\subsection{Analysis of Variance}

[22] One crucial question regarding the 12 meteorological data sets collected by the sensor network is whether 


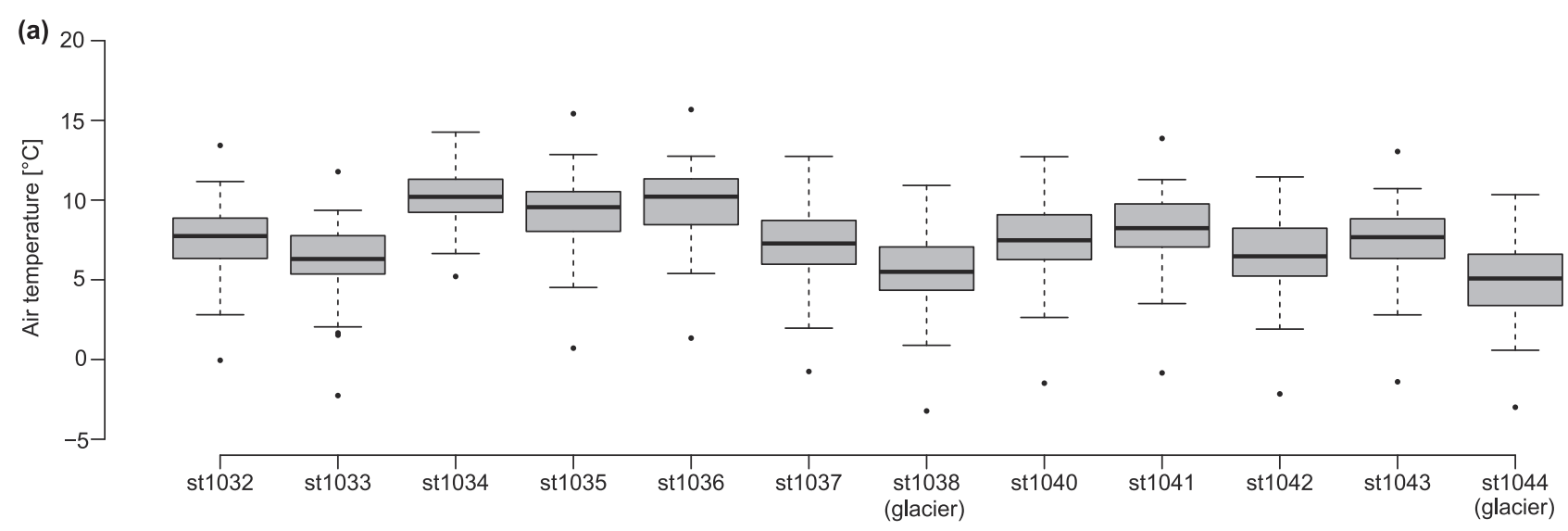

(b)

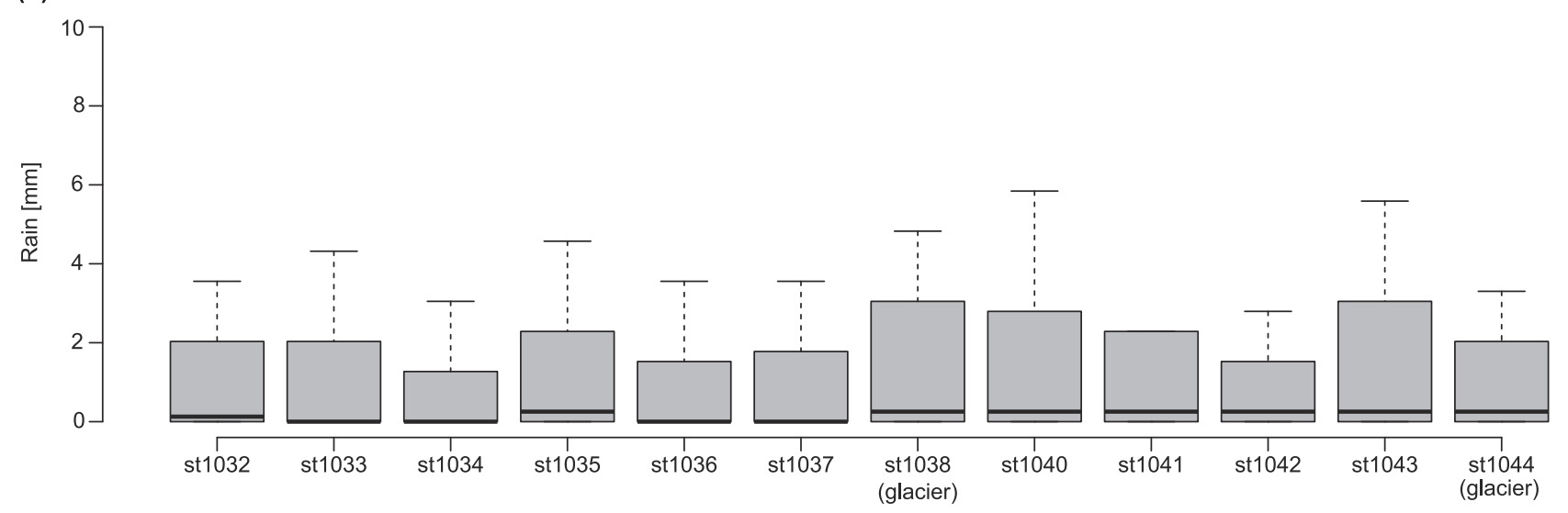

Figure 5. Box plots of (a) daily mean air temperatures and (b) daily precipitation from mid-September to mid-October 2009.

they belong to the same statistical population or not. To evaluate this, we need to verify if the total variance is explained by the variance of each individual data set (group) or by the variance between each data set.

[23] The variance within the group means that the variability is intrinsic to the process itself and that it is independent of the location where it was measured. On the other hand, when there exists a variance between each group, there is a variability linked to the location where the data were collected. In this case, the intrinsic variability of the variable is enhanced by external factors such as morphology and orographic effects.

[24] There are several techniques to investigate data variability. Analyses of variance (ANOVAs) are typically used for this purpose, provided that all data sets are independent, are normally distributed, and share the same variance. Since this is not necessarily the case for air temperature or rainfall, we use a nonparametric test, the Kruskal-Wallis test [Kruskal and Wallis, 1952; Ernst, 2004]. Different from ANOVA, the Kruskal-Wallis test is based on ranking observations such that an assumption of normality is not necessary. It compares the medians of three or more unpaired groups; values are ranked from low to high, and analyses are based on the distribution of those ranks. For each group, ranks are summed, and discrepancies among sums are combined in a statistic that follows a $\chi^{2}$ distribution. Larger values of this statistic correspond to larger discrepancies among rank sums. The hypothesis testing is formed by the null hypothesis $H_{0}$, which states that samples were drawn from the same population, and the alternative hypothesis $H_{1}$, which states that samples were drawn from different populations, sharing the same shape but with different central tendencies (medians). If the $p$ value is less than the confidence interval (usually set to 0.05 ), then the differences observed among the groups cannot be attributed simply to the variability within the same population. Alternatively, a $p$ value larger than the confidence interval does not contain enough information to conclude that the group medians differ. The sample size has a great bearing on the capability of the test to detect true differences among groups. Thus, small sample sizes do not guarantee reliable results. For large sample sizes, however, the test can be as powerful as an ANOVA.

[25] Since the test does not require all groups to have the same data size, the Kruskal-Wallis test was applied for two different periods. The first time data were taken from the nine stations that measured data continuously from midJune to mid-October (1032-1037 and 1040-1043); the second time the two stations operating from mid-September to mid-October on the glacier were added. An additional "event-based precipitation" category was also included for cases in which rainfall was measured by at least two stations inside the catchment. The statistical results are presented in Table 1.

[26] Results from the Kruskal-Wallis test highlight that the discrepancies among data collected at different 
Table 1. Kruskal-Wallis Test Results for Precipitation and Air Temperature Daily Data ${ }^{\mathrm{a}}$

\begin{tabular}{lccc}
\hline Meteorological Variable & Number of Stations & $\chi^{2}$ & $p$ Value \\
\hline Precipitation & 9 & 18.766 & 0.01616 \\
Precipitation & 12 & 20.5649 & 0.03817 \\
Event-based precipitation & 9 & 24.6431 & 0.00179 \\
Event-based precipitation & 12 & 3.5557 & 0.9812 \\
Air temperature & 9 & 130.309 & $<2.2 \times 10^{-16}$ \\
Air temperature & 12 & 232.083 & $<2.2 \times 10^{-16}$ \\
\hline
\end{tabular}

${ }^{a}$ Here $\chi^{2}$ represents the test variable, which is distributed as $\chi^{2}$, and the $p$ value has to be compared to the level of significance $\alpha=0.05$.

locations cannot be attributed to random variability within the group. As discussed, the fact that the $p$ values are smaller than 0.05 confirms the existence of a variability linked to the location where data were collected. However, results for the event-based precipitation with the 12 stations functioning from mid-September to mid-October do not provide enough information to conclude that data were sampled from more than one statistical population. Indeed, in this case $p>0.05$. This could be due to the short sampling

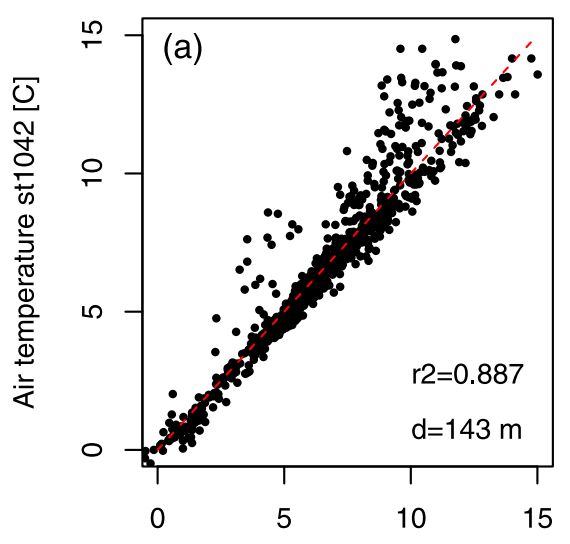

Air temperature st1033 [C]

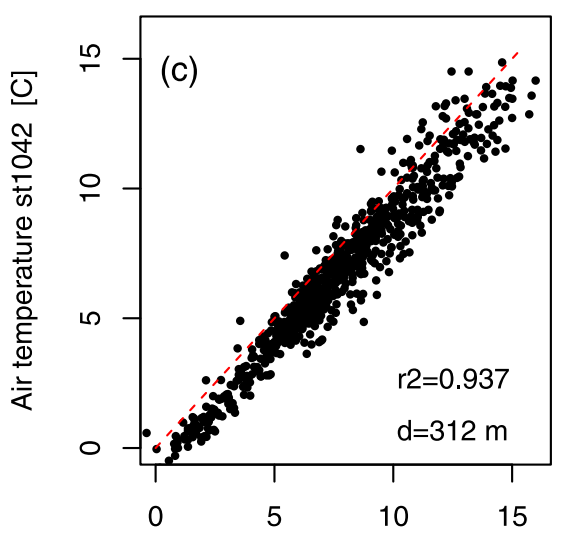

Air temperature st1040 [C] period ( 1 month) or to the fact that precipitation events during this period of the year are less likely to originate from convective activity. Consequently, the rainfall would be more uniformly distributed than in summertime, where we observed important spatial variability $(p<0.05)$.

\subsection{Spatial Correlations}

[27] Time series from all the stations were selected over a common data window. The measurements were quality controlled and averaged at hourly intervals, and then each pair of stations was analyzed. Figure 6 shows four of these scatterplots for air temperature with different ranges of distances between the stations. Regardless of the distance between the stations and the different morphological features associated with their locations, the data remain highly correlated. Stations 1033 and 1042 (Figure 6a) were located roughly at the same elevation, on the ridge bordering the watershed on its northwestern side. For these stations the data were highly correlated $\left(r^{2}=0.887\right)$. Stations 1038 and 1044 (Figure 6b) were installed on the glacier at 2501 and $2531 \mathrm{~m}$ asl, respectively (see also Figure 1), $240 \mathrm{~m}$ apart. Although there are a few outliers, at these stations the

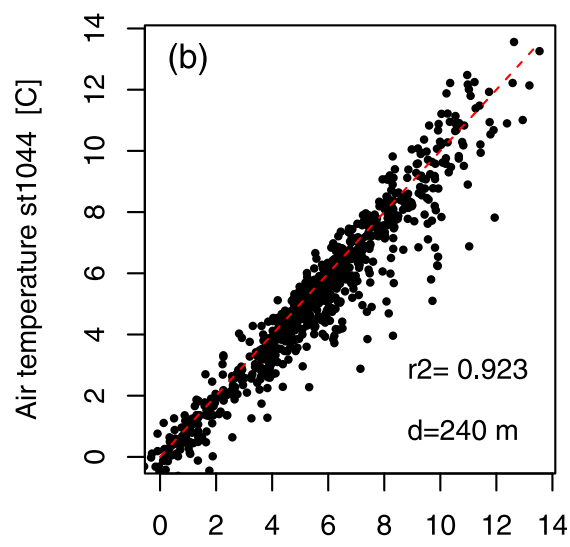

Air temperature st1038 [C]

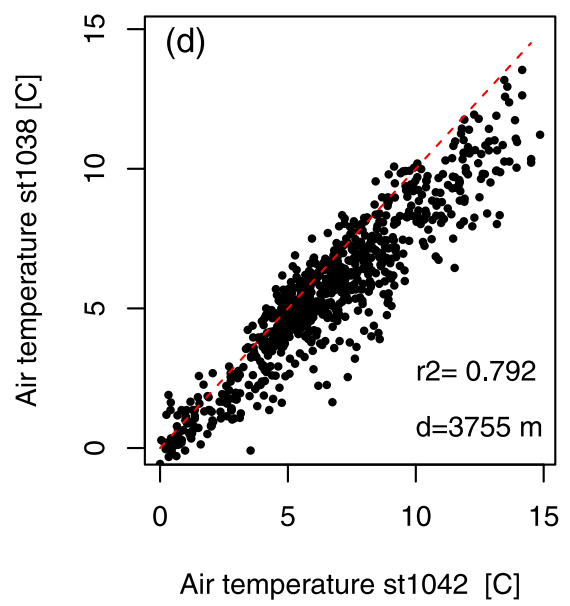

Figure 6. Scatterplots of hourly air temperature data recorded at five different locations within the study area are displayed in four pairs: (a) 1033 and 1042, (b) 1038 and 1044, (c) 1040 and 1042, and (d) 1042 and 1038. The Euclidean distance calculated between the stations accounts for differences in elevation. A red 1:1 line is displayed for comparison purposes. 

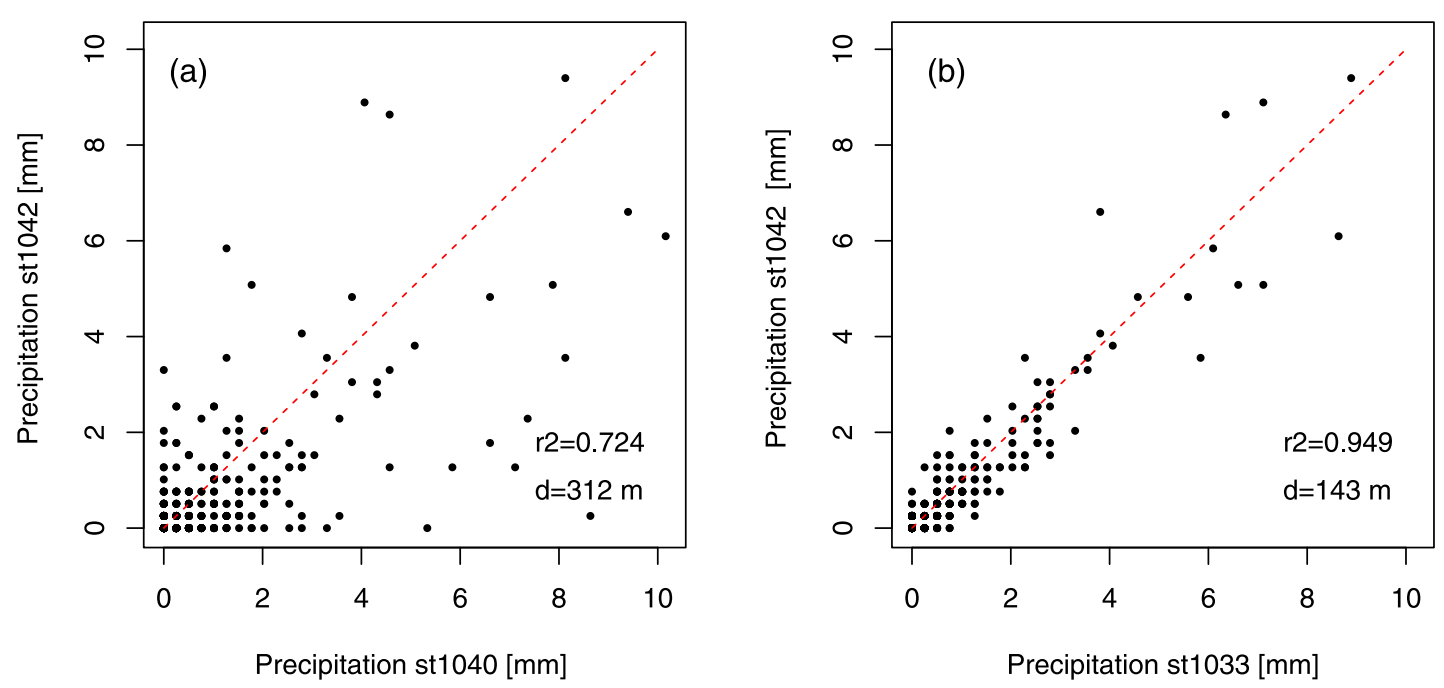

Figure 7. Comparison between hourly rainfall measured at three different locations. The scatterplots display the dependence between two pairs of stations: (a) 1042 and 1040 and (b) 1042 and 1033, 182 and $130 \mathrm{~m}$ apart, respectively. Although these three stations are located on the same side of the watershed, two of them show a structure of dependence (stations 1042 and 1033), whereas stations 1042 and 1040 show a significative difference in the rainfall records.

temperature data are well correlated $\left(r^{2}=0.923\right)$. Stations 1040 and 1042 (Figure 6c) were located on the same side of the catchment at 2259 and $2426 \mathrm{~m}$ asl, respectively, and had a coefficient of determination of $r^{2}=0.937$. Observations from station 1038 were generally cooler than those recorded at station 1042 (Figure 6d) for mainly two reasons. First, station 1042 was installed at a lower elevation than station 1038 (roughly $100 \mathrm{~m}$ below). Second, station 1038 was deployed directly over the glacier; its air temperature measurements were thus affected by the surrounding cold air mass.

[28] Figure 7 shows two scatterplots for rainfall data with different distances between the stations on the same slope. The correlation for the pair 1042 and 1040 is low $\left(r^{2}\right.$ $=0.724$; Figure 7a), whereas for the pair 1042 and 1033, rainfall data are highly correlated $\left(r^{2}=0.949\right.$; Figure $\left.7 \mathrm{~b}\right)$. This suggests that the correlation between pairs of stations could be related to their distance. To explore this in more detail, the linear correlation coefficient was computed for each pair of weather stations. Figure 8 shows, for rainfall data, the linear correlations for each pair of stations in the watershed as a function of their relative Euclidean distance. The linear correlation between the stations shows a decreasing trend with distance, indicating the presence of some structure of spatial variability. On the contrary, a similar trend was not found for air temperature data.

\subsection{Air Temperature Lapse Rates}

[29] Having shown the existence of spatial variability in the data sets, the impacts of the time of day, the elevation, the slope and the aspect on air temperature are analyzed to obtain further insight into the spatial variability of air temperature. The dependence of air temperature upon elevation is investigated by computing the vertical lapse rate every three hours (Table 2). Part of these observations is also plotted in Figure 9. The average observed lapse rates

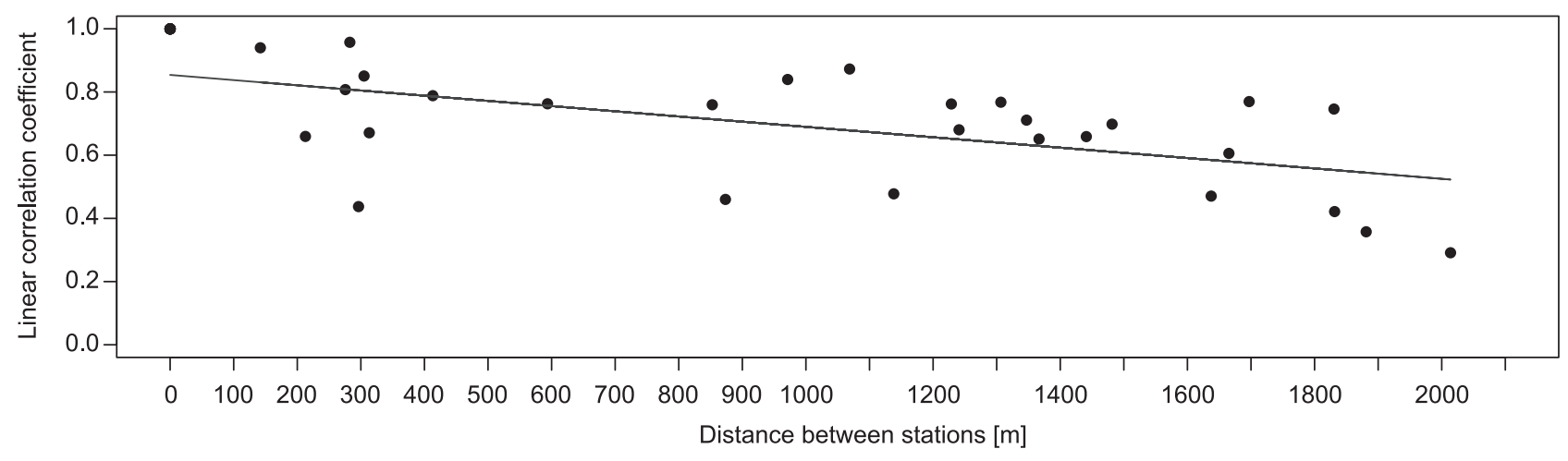

Figure 8. The linear correlation coefficient computed for hourly rainfall data from all the possible pairs of stations (represented as dots) versus their relative distance. The straight line is a linear fit. We excluded stations 1041 and 1037 because of some initial recording error and the two stations on the glacier (1038 and 1044) that did not cover the entire period. 
Table 2. Average Lapse Rates Computed at $3 \mathrm{~h}$ Intervals for All Stations and the Associated Coefficients of Determination

\begin{tabular}{ccc}
\hline Time of Day (LT) & Lapse $\operatorname{Rate}^{\mathrm{a}}\left({ }^{\circ} \mathrm{C} \mathrm{km}^{-1}\right)$ & $r^{2}$ \\
\hline $00: 00$ & -4.9 & 0.95 \\
$03: 00$ & -4.8 & 0.90 \\
$06: 00$ & -4.1 & 0.61 \\
$09: 00$ & -9.5 & 0.88 \\
$12: 00$ & -10.4 & 0.89 \\
$15: 00$ & -7.7 & 0.84 \\
$18: 00$ & -5.5 & 0.97 \\
$21: 00$ & -5.2 & 0.96 \\
\hline
\end{tabular}

${ }^{\text {a }}$ The dry adiabatic lapse rate is $-9.8^{\circ} \mathrm{C} \mathrm{km}^{-1}$.

changed from stable to unstable atmospheric stability during the course of the day, ranging from $-4.1^{\circ} \mathrm{C} \mathrm{km}^{-1}$ at 06:00 LT to $-10.4^{\circ} \mathrm{C} \mathrm{km}^{-1}$ at 12:00 LT and then back to $-5.2^{\circ} \mathrm{C} \mathrm{km}^{-1}$ at $21: 00 \mathrm{LT}$. On average, morning temperature profiles (around 09:00 LT) were nearly neutral, the atmosphere at noon was unstable, and during the rest of the day, stable atmospheric stability conditions prevailed.
[30] To disentangle the roles individually played by elevation and aspect on air temperature, the radial plots in Figure 10 were developed. On the basis of the lapse rates displayed in Figure 9, the residuals for each station at every hour were computed. These residuals were normalized using the air temperature values for the given time averaged over the duration of the experiment.

[31] Figure 10 depicts radial plots where the differences between the fitted lapse rates (see Table 2 and Figure 9) are analyzed with respect to the aspect (exposure to the sun) of the slope where the stations were installed. Thus, points on the inner part of the bold circle indicate negative residuals, meaning that the corresponding station, on average, measured temperatures colder than those of the fitted average lapse rate. On the other hand, points outside the bold circle indicate positive residuals, meaning that, on average, the station measured warmer temperatures than the fitted lapse rate.

[32] East facing stations (1033, 1040, 1041, 1042, and 1043) reflect morning heating (Figure 10a), while the west facing stations remain colder. Note that at all times the stations on the glacier remain relatively colder than the others.

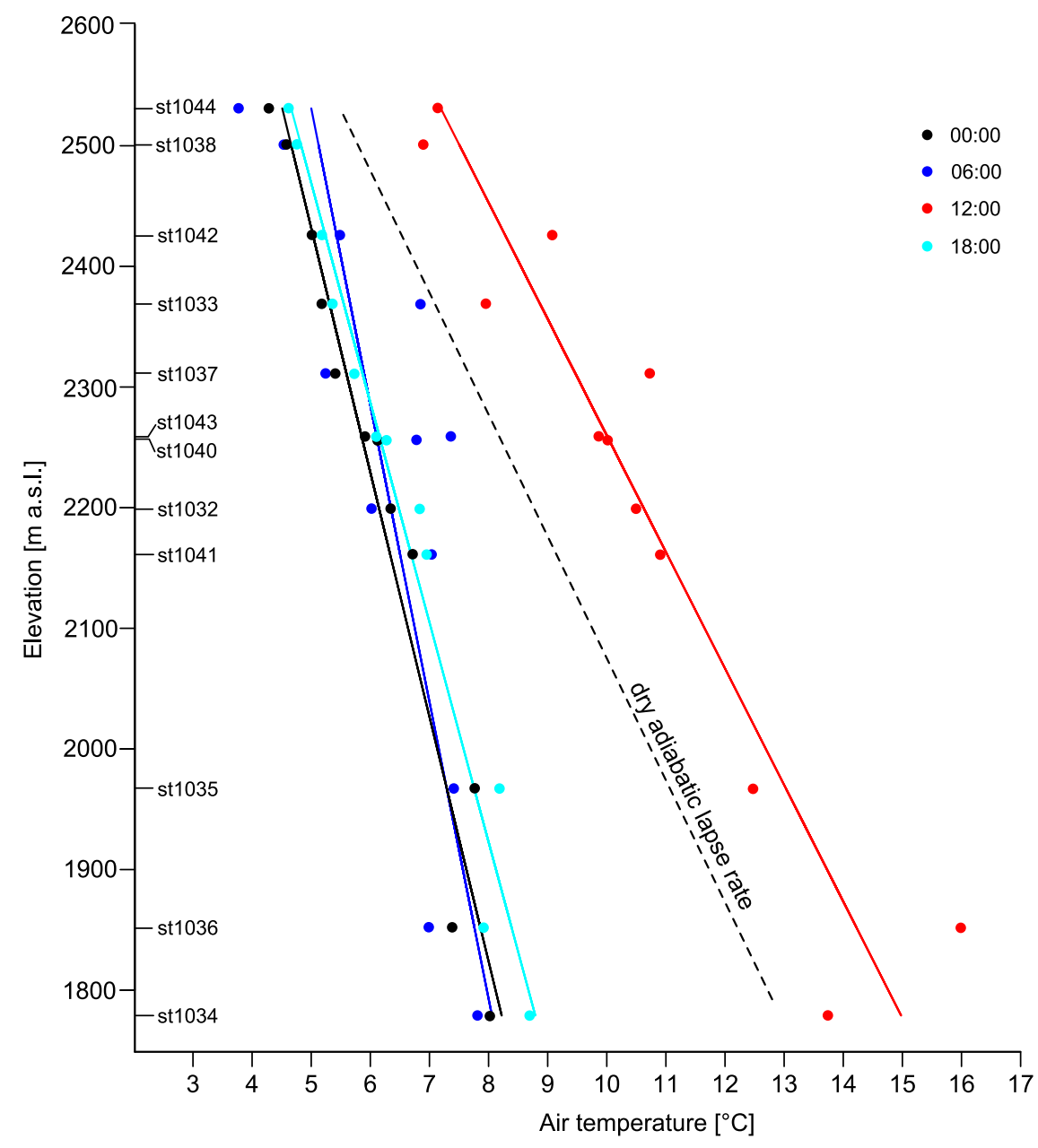

Figure 9. Average lapse rates computed over $3 \mathrm{~h}$ intervals for all stations. For clarity purposes, only the lapse rates calculated at 00:00, 06:00, 12:00, and 18:00 LT are presented (the others are found in Table 2). Points on the diagram represent the 3-hourly averaged temperature values, averaged over the entire period (June-October 2009) for the corresponding station. The dry adiabatic lapse rate $\left(-9.8^{\circ} \mathrm{C}\right.$ $\mathrm{km}^{-1}$ ) is the black dashed line. 

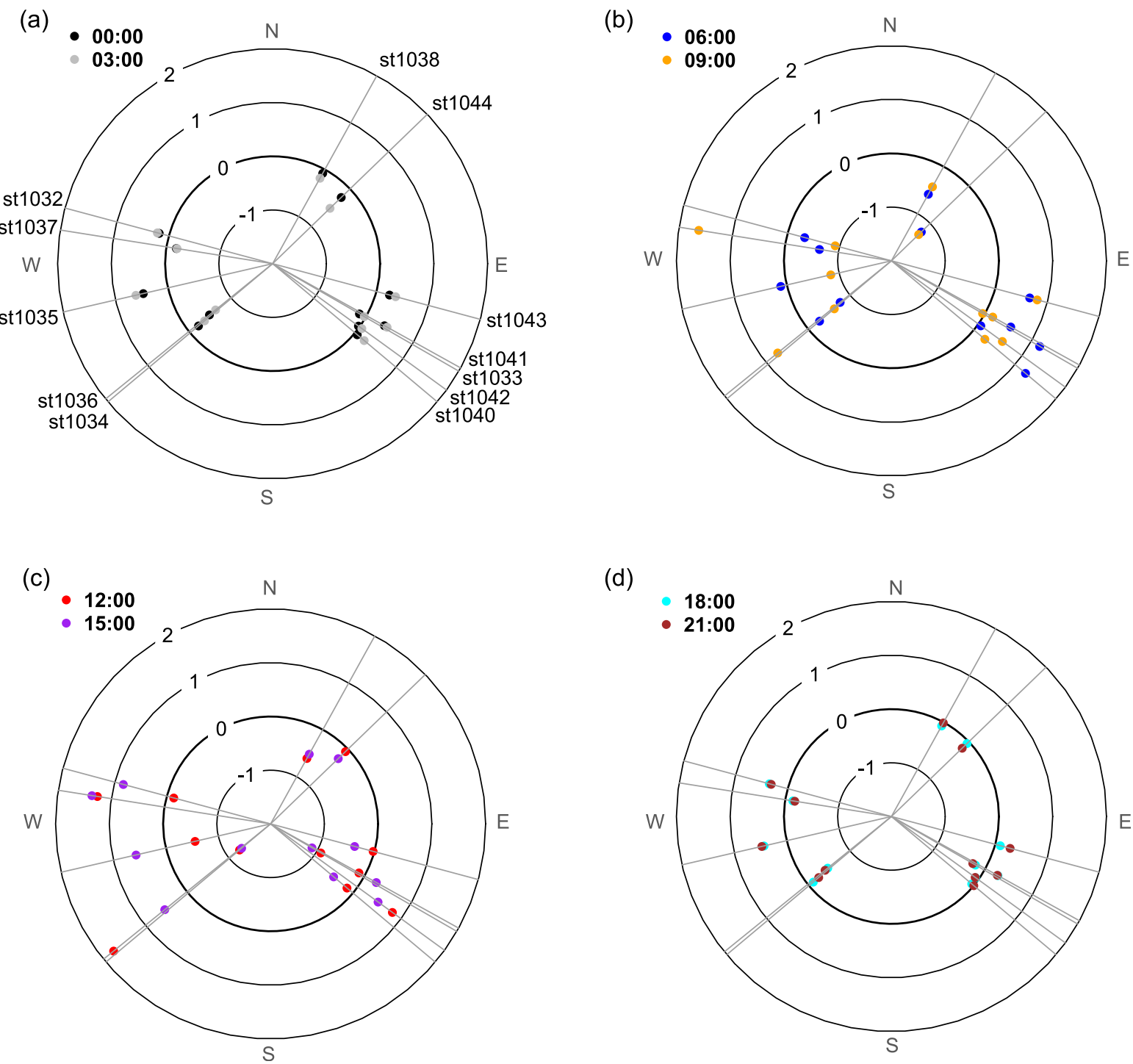

Figure 10. Radial plots representing the effect of aspect on air temperature relative to the fitted lapse rate (see Figure 9) at different times during the day: (a) from 04:30 to 10:30 LT, (b) from 10:30 to 16:30 LT, (c) from 16:30 to 22:30 LT, and (d) from 22:30 to 04:30 LT. The angles identified by each radius represent the aspect of the slope where the station is installed. Stations on slopes facing north would be aligned with the label "N," for instance. For each station, the difference between the average air temperature recorded over the period and the fitted lapse rate for all stations is calculated. Points located on the bold circle mean that the measured air temperatures were equal, on average, to the fitted lapse. Points inside (outside) the bold circle are related to air temperature data smaller (greater) than the fitted lapse rate. The temperature step is $1^{\circ} \mathrm{C}$.

The analysis of these radial plots reveals that stations on the glacier (1038 and 1044) always show temperatures colder than the fitted lapse rate would predict because of the cooling mass (rock and ice) surrounding them. The importance of the diurnal solar heating and shadows in the steep topography is clear. The stations on the west facing side have temperatures that are colder than the average measured lapse rate in the morning (two of them also at noon) and warmer in the afternoon. The opposite holds for stations on the east facing side; they are warmer than the fitted lapse rate in the morning and colder in the afternoon. In addition, on the west facing slope the thermal behavior is not symmetrical if compared to the east facing slope at sunrise and sunset. This is due to the complex geometry inside the valley, with milder topography on the east facing slopes and steeper terrain on the west facing slopes (see Figure 1). After the sunset (Figure 10a), the aspect does not play a role any longer, and the points are randomly scattered around the dashed circle.

[33] Patterns of local air temperature are important as the micrometeorology will influence snowmelt rates, local rates of evaporation, the antecedent soil moisture, and ultimately, the hydrologic response to storms [Brutsaert, 1986; Parlange et al., 1995]. These patterns can only be 
captured by distributed sensors installed at locations characterized by different morphological features and shading.

\section{Hydrological Modeling}

[34] Streamflow generation involves a range of nonlinear processes whose realistic description (and thus modeling) is challenging [Zecharias and Brutsaert, 1988; Stagnitti et al., 1992]. Two of the main sources of complexity include the nonlinear response of the watershed to variable meteorological forcings and their spatial variability as previously discussed.

[35] If the motivation behind the use of a hydrological model is to forecast discharge for flood protection, a simple lumped hydrological model can be an appropriate tool. It has the advantage of being easy to calibrate, and it requires a limited amount of data. However, it does not capture the essence of the hydrological processes that generate streamflow, such as antecedent soil moisture changes as a consequence of infiltration, evaporation, subsurface flows, and other processes linked to vegetational surface energy balance or glacier dynamics. One could argue that lumped models depend on empirical parameters that are not transferrable to other sites or from one season to another. Nonetheless, Carenzo et al. [2009] have found that a lumped model calibrated over a Swiss glacier during a specific season could be used without recalibration at other similar sites and over different years with a small decrease in the performance of the modeled snow and ice melt rates.

[36] Despite the large amount of data required, a 3-D distributed model, in principle, allows for a more comprehensive representation of the processes and cause-effect relationships [Kampf and Burges, 2007]. Provided the availability of the forcing data (which is typically not the case [see Sivapalan, 2003]) soil characterization data, and data to derive boundary and initial conditions, a 3-D model can reproduce part of the physics lost in lumped models and the measured streamflow observations themselves. In addition, a distributed and physically based approach can be a powerful tool to investigate the impact of spatial variability of the forcing on the hydrological response. Indeed, a 3-D model can compute surface runoff and infiltration according to the precipitation measured or interpolated at each grid point and eventually redistribute them, according to topography and soil hydraulic characteristics as well as local evaporation. However, given that one of the goals of this work is to assess the impact of spatial variability of meteorological forcing on streamflow generation, which is an aggregated output, we decided to use a lumped model to eliminate sources of complexity linked to the model itself, in combination with weather data from each station. This test allowed us to disentangle the role played by distributed data on aggregated output.

\subsection{The Lumped Model}

[37] A simple lumped model, fed by precipitation and air temperature data, was calibrated for each Sensorscope station by comparing the modeled outflow with the measurements.

\subsubsection{Description}

[38] The analysis in section 3 highlighted the four main components to the discharge: snowmelt, ice melt, rainfall runoff, and base flow. These components have been filtered out and investigated separately in correlation with temperature and precipitation to quantify their reciprocal interactions and infer the essence of the hydrologic system dynamics.

[39] Strong correlations between near-surface air temperatures and snowmelt runoff have frequently been reported [Zuzel and Cox, 1975; Braithwaite, 1981]. It is thus not a surprise that the temperature index method is still widely used in several poorly gauged mountainous regions of the world like the Alps [Schaefli et al., 2005; Bocchiola et al., 2010] or the Himalayas [Singh et al., 2000], even if air temperature is challenging to measure because of radiative loading [Huwald et al., 2009]. Ohmura [2001] provides a useful argument for the physical basis of the temperaturebased melt index method. Several studies have included a radiation component to the classic degree-day model [Kustas et al., 1994; Cazorzi and DallaFontana, 1996] or other refinements like the effect of dust deposition over snow and ice on the empirical degree-day factors [Singh et al., 2000].

[40] On the basis of the strong correlation between both hourly and daily average temperatures and snowmelt, we modeled the snowmelt runoff by using a basic degree-day approach. Our observations also revealed that the snow volume melted in a day was highly correlated to daily averaged air temperatures, whereas the shape of "melting waves" depended mostly on hourly averaged air temperatures. The simple degree-day formulation [Hock, 2003] was thus modified to account for both daily and hourly average temperatures. In addition, the formulation was adapted to account for the residence time in the network (time shift between temperature and discharge peaks $\hat{t}$ ) and for the progressive decrease of the areal snow cover. The snowmelt runoff was described by

$$
\begin{aligned}
Q_{\text {snow }}(t) & =f_{m_{\text {soow }}}\left[T_{d}-T_{0}\right]\left[T_{h}(t-\hat{t})-2 T_{0}\right] \alpha(t), \quad T_{d}, T_{h} \geq T_{0}, \\
& =0, \quad T_{d}, T_{h}<T_{0},
\end{aligned}
$$

where

$$
\begin{aligned}
\alpha(t) & =\min \left(\frac{t}{t^{\prime}}, 1-\frac{t}{t^{\prime}}\right), \quad t \leq t^{\prime}, \\
& =0, \quad t<t^{\prime},
\end{aligned}
$$

where $Q_{\text {snow }}$ is the snowmelt runoff, $f_{m_{\text {snow }}}$ is the melt factor for snow [Hock, 2003], $T_{d}$ and $T_{h}$ are the daily and hourly mean air temperatures, respectively, $T_{0}$ is the air temperature threshold above which snowmelt becomes significant (Table 3), and $\alpha(t)$ is a time-dependent triangular function to account for the changing melt factors during the melt season [Kuusisto, 1980]. The high values of threshold temperatures could possibly reflect the fact that a correction for radiative errors was not applied to the data [Huwald et al., 2009]. The snowmelt runoff depends on the interplay between the main the sources of energy available for melting (solar radiation, sensible and latent heat fluxes, and warm-air advection), the extent of the snow-covered area, and the snowpack depletion rate [Anderson, 1968]. The highest streamflows were observed at the end of June (see Figures $4 \mathrm{a}$ and 11), followed by a slow decrease until midJuly (represented by $t^{\prime}$ in (3)). Past this period, the snowpack was completely depleted. 
Table 3. Station List and Details ${ }^{\mathrm{a}}$

\begin{tabular}{ccccccccccc}
\hline Station & Elevation $(\mathrm{m}$ asl $)$ & Aspect $(\mathrm{deg})$ & Location & $f_{m}\left(\mathrm{~m}^{3} \mathrm{~s}^{-1}{ }^{\circ} \mathrm{C}^{-1}\right)$ & $\hat{t}(\mathrm{~h})$ & $K\left(\mathrm{~h}^{-1}\right)$ & Nash & $T_{0}\left({ }^{\circ} \mathrm{C}\right)$ & $T_{0 \text { ice }}\left({ }^{\circ} \mathrm{C}\right)$ & Distance $(\mathrm{m})$ \\
\hline 1032 & 2199 & 285 & right & 37 & 4 & 0.04 & 0.953 & 2.0 & 5.0 & 1204 \\
1033 & 2369 & 120 & left & 50 & 5 & 0.04 & 0.950 & 2.0 & 5.0 & 2444 \\
1034 & 1779 & 230 & right & 20 & 3 & 0.07 & 0.890 & 3.0 & 5.0 & 96 \\
1035 & 1967 & 2 & right & 43 & 3 & 0.04 & 0.948 & 3.0 & 5.0 & 829 \\
1036 & 1852 & 257 & right & 18 & 4 & 0.04 & 0.914 & 3.0 & 5.0 & 450 \\
1037 & 2311 & 279 & right & 15 & 4 & 0.05 & 0.891 & 3.0 & 5.0 & 1554 \\
1038 & 2501 & 29 & glacier & & & & & & & 578 \\
1040 & 2259 & 130 & left & 35 & 5 & 0.05 & 0.956 & 2.0 & 4.0 & 2462 \\
1041 & 2161 & 119 & left & 17 & 5 & 0.04 & 0.908 & 3.0 & 5.0 & 2328 \\
1042 & 2426 & 126 & left & 35 & 5 & 0.05 & 0.949 & 2.0 & 3.5 & 2885 \\
1043 & 2256 & 105 & left & 35 & 6 & 0.05 & 0.944 & 3.0 & 5.0 & 1233 \\
1044 & 2531 & 46 & glacier & & & & & & & 6077 \\
Averaged & & & & 35 & 4 & 0.04 & 0.920 & 2.0 & 4.0 & \\
\hline
\end{tabular}

${ }^{a}$ Right and left refer to the orographic side of the watershed depicted in Figure $1, f_{m}$ is the melt factor, $\hat{t}$ is the time shift between temperature and discharge peaks, $K$ is the constant rate for the linear reservoir model, Nash is the Nash index computed for the simulated discharge using the lumped model, $T_{0}$ and $T_{0_{\text {ice }}}$ are the threshold temperatures for the degree-day models generating the snow and ice melt streamflow component, and distance is the distance from the outlet.

[41] The melting factor $f_{m_{\text {sow }}}$ is a calibration parameter. It was found to vary from one Sensorscope station to the other, ranging from 15 to $50 \mathrm{~L} \mathrm{~s}^{-1}{ }^{\circ} \mathrm{C}^{-1}$ (see Table 3). No relationships between melt factor and elevation or aspect could be found. On the other hand, the time shift $\hat{t}$ in the discharge (see (2) and (4)) showed a positive linear trend with both elevation and distance to the catchment outlet, increasing from $3 \mathrm{~h}$ for the closest stations to $6 \mathrm{~h}$ for the farthest stations.
[42] The ice melt runoff was also modeled using a degree-day model:

$$
\begin{aligned}
Q_{\text {ice }}(t) & =f_{m_{\text {ice }}}\left[T_{h}(t-\hat{t})-T_{0_{\text {ice }}}\right], \quad T_{h} \geq T_{0_{\text {ice }}}, \\
& =0, \quad T_{h}<T_{0_{\text {ice }}},
\end{aligned}
$$

where $Q_{\text {ice }}$ is the glacier melt runoff, $f_{m_{\text {ice }}}$ is the melt factor for ice, and $T_{0_{\text {icc }}}$ is a calibration parameter. The melt factor for ice was found to be constant $\left(15 \mathrm{~L} \mathrm{~s}^{-1}{ }^{\circ} \mathrm{C}^{-1}\right)$ from one
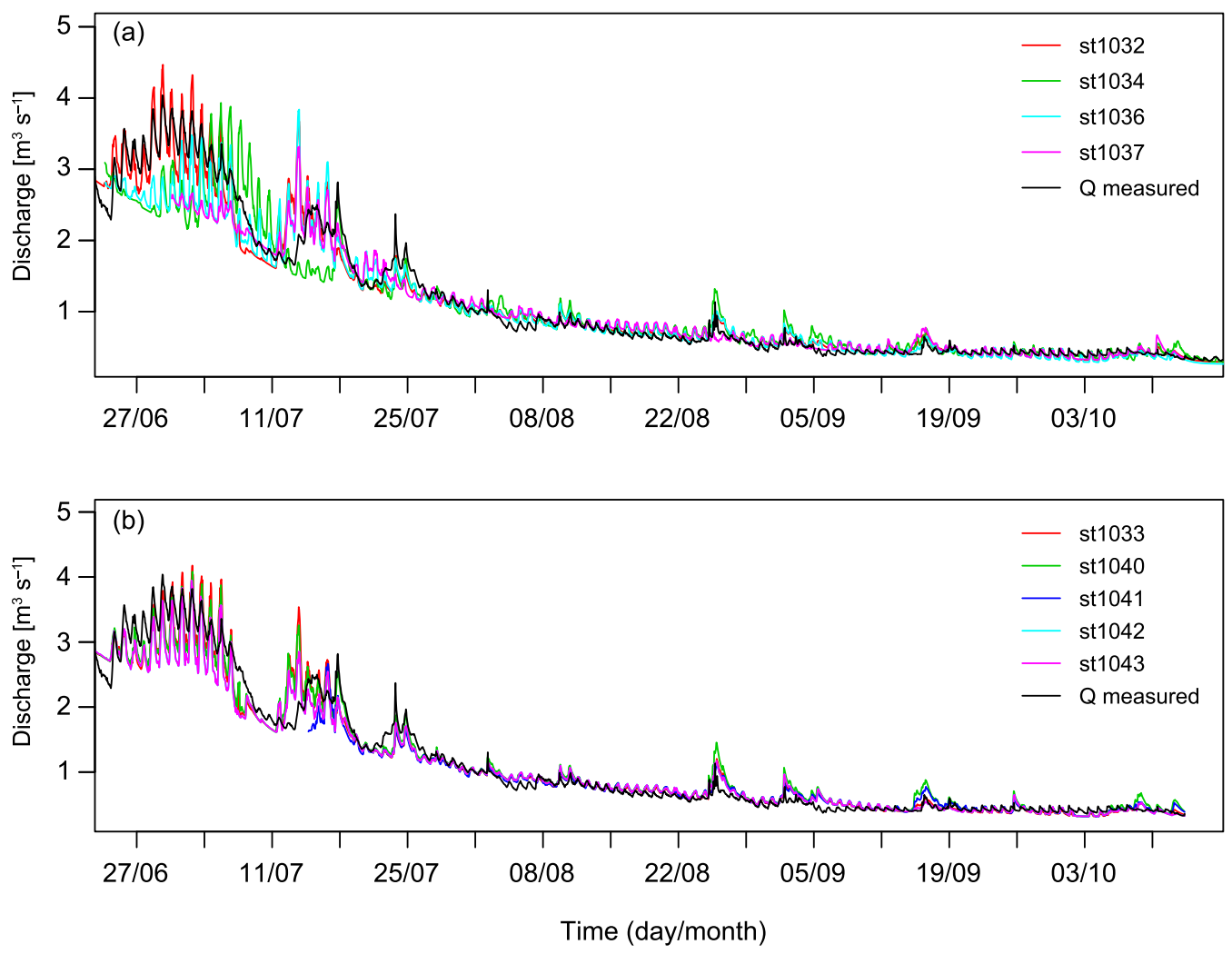

Figure 11. Simulated streamflow obtained with the lumped model using nine different meteorological data sets. (a) Results obtained using data from stations located on the orographic right side of the catchment $(1032,1034,1036$, and 1037) versus the measured discharge. (b) Results obtained using data from stations located on the hydrorographic left side of the catchment $(1033,1040,1041,1042$, and 1043) versus the measured discharge. 
Sensorscope stations to another and was smaller than the snowmelt factor presented by Hock [2003]. The calibration parameter $T_{0_{\text {ice }}}$ slightly changed among stations (Table 3 ).

[43] This ice melt runoff model assumes that the glacier area does not decrease with time, and therefore, the only factor affecting stream feeding is temperature. Other ice melt models [e.g., Gottlieb, 1980] assume that ice melt does not take place before the glacier is completely snow free. In this case, ice melt runoff is allowed as long as the air temperature is greater than $T_{0_{\text {ice }}}$. As previously stated for the snowmelt, air temperature measures were not corrected for radiative errors [Huwald et al., 2009]; therefore $T_{0_{\text {ice }}}$ should not a priori be considered as a physical threshold.

[44] The rainfall-runoff contribution to streamflow was modeled using the linear reservoir approach [Dooge, 1973], which takes the form

$$
Q_{\text {rain }}(t)=A \int_{0}^{t} \frac{e^{-\frac{\tau}{k}}}{k} I_{e}(t-\tau) \mathrm{d} \tau
$$

where $A\left[L^{2}\right]$ is the watershed area $\left(20 \mathrm{~km}^{2}\right), k$ is the reservoir constant $\left[T^{-1}\right]$ (a calibration parameter), $I_{e}$ is the effective precipitation $\left[L T^{-1}\right]$ (calculated by applying a runoff coefficient to the measured precipitation), and $\tau$ is a dummy variable of integration. The remaining portion of precipitation either evaporates or infiltrates, thus feeding the base flow.

[45] Discharge data showed evidence of a base flow characterized by an exponential decay shape (see Figure 4), reaching maximum values of $3 \mathrm{~m}^{3} \mathrm{~s}^{-1}$ in mid-June and minimum values of $0.250 \mathrm{~m}^{3} \mathrm{~s}^{-1}$ at the end of October. This base flow was also described using the linear reservoir approach:

$$
Q_{\text {base }}(t)=K_{\infty}+\left(K_{0}-K_{\infty}\right) e^{-\frac{t}{K}}
$$

where $K_{\infty}$ is the minimum discharge at the end of October $\left(0.250 \mathrm{~m}^{3} \mathrm{~s}^{-1}\right), K_{0}$ is the initial value of the base flow $\left(3 \mathrm{~m}^{3} \mathrm{~s}^{-1}\right)$, and $K$ is the decay parameter of the seasonal trend $(680 \mathrm{~h})$. The initial storage of watershed due to accumulation processes can be given as $S=K_{0} K\left(\mathrm{~m}^{3}\right)$.

\subsubsection{Results}

[46] To assess the impact of spatial variability of meteorological forcing on streamflow generation, the lumped model was applied separately to the nine experimental data sets collected by the Sensorscope stations operational during the 4 month period (late June through October). Thus, nine different discharge outputs were obtained and compared to the measured streamflow (Figure 11). Calibration parameters were fitted by minimizing the residuals between the simulated and measured discharges.

[47] Results show that the spatial variability of the meteorological forcing had different impacts on the diverse components of streamflow generation. Since the snowmelt was mainly controlled by air temperature, the input temperature data play a role in determining the shape and the timing of the discharge (Figure 11), especially between the end of June and mid-July, when the discharge was mainly due to snowmelt. As seen in Figure 11, there was more variability in the modeled streamflow during that period than for the rest of the experiment. This variability was likely due to the spatial heterogeneity in the snow cover and the air temperature. There are very few differences between the modeled discharge past mid-July. This seems to indicate that the base flow and the ice melt discharge are relatively insensitive to the spatial variability of the forcing. For the ice melt this is probably because the glacier is rather small and covers a very limited portion on the watershed $(\approx 4 \%)$. Therefore, the air temperature could be considered constant over this area.

[48] In addition, the model was run by using the meteorological forcing data averaged among all the stations. Figure 12 shows that the streamflow obtained using the spatially

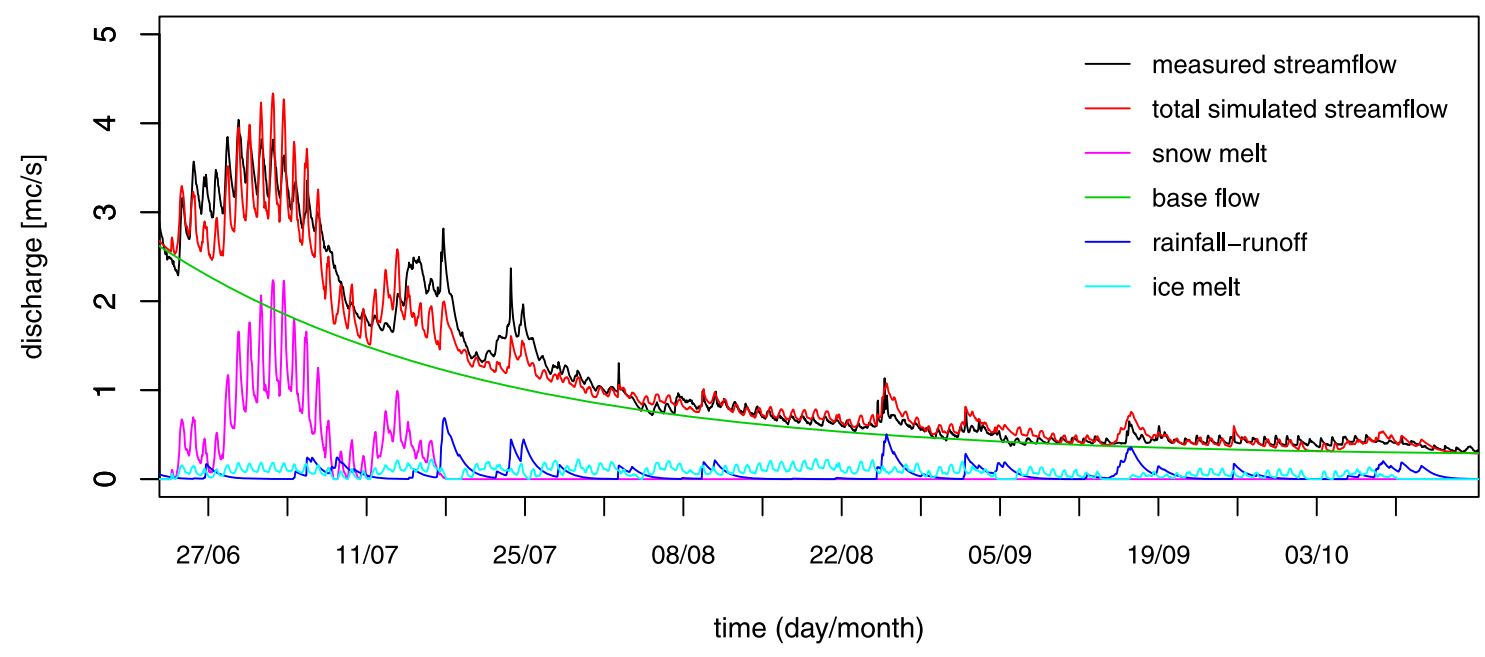

Figure 12. Simulated discharge (red line) obtained with the lumped model using spatially averaged air temperatures compared to streamflow measurements (black line). The four modeled components contributing to the streamflow are displayed with different colors: the snowmelt runoff (pink line), the ice melt runoff (light blue line; see (3)), the rainfall runoff (dark blue line; see (5)), and the base flow (green line; see (6)). 
averaged input data does not significantly differ from those obtained using meteorological forcing data from any single station (see Figure 11). For this test case, the four main components of the streamflow are shown (see Figure 12). Over the experimental period, the base flow is the dominating component, except for a short period in early July when the snowmelt exceeded it. As discussed, the snowmelt runoff is important until mid-July, with large diurnal fluctuations of up to $\approx 1 \mathrm{~m}^{3} \mathrm{~s}^{-1}$. The daily mean ice melt runoff is relatively constant, and its signature becomes discernable around mid-July. Rainfall runoff is associated with a dozen precipitation events, all of which generate peak discharges less than $0.6 \mathrm{~m}^{3} \mathrm{~s}^{-1}$.

[49] Overall, the snowmelt, the ice melt, and the base flow were all fairly well captured by the lumped model, indicating that for the specific purposes of streamflow generation analysis, the spatial variability of the forcing could be lumped in homogeneous values. However, the peaks generated by rainfall runoff were not well captured by the model (see Figure 12 around 24-25 August 2009, for instance). By definition, the lumped model assumes a homogeneous rainfall over the entire watershed. Therefore, it cannot incorporate either the spatial variability of precipitation inside the catchment or the dynamics of infiltration and redistribution processes (which determine the timing of peak). These phenomena can only be integrated through the reservoir constant $K$, which is theoretically different for each flow path (from the station to the stream network; see Table 3).

\section{Discussion and Conclusions}

[50] The spatial variability of air temperature and rainfall data collected during a 4 month field deployment in the Swiss Alps was quantified (Table 1). The variability of these variables was studied through the analysis of variance, which highlighted that data were sampled from different statistical populations. The variation in air temperature and rainfall could be partially explained by the varying morphological features of the catchment, such as the elevation and the aspect of the surface, and partly by the time of the day (Figures 9 and 10).

[51] A lumped linear model was then used to identify the hydrological processes governing streamflow, such as ice melt, base flow, and snowmelt, and to assess the impact of spatial variability of meteorological forcing on streamflow generation. Results show that part of the streamflow can be accurately described using a lumped model. The snowmelt runoff is sensitive to spatial variability of air temperature, but a relatively good description of the streamflow hydrograph can be obtained with the lumped model even if an average air temperature field is taken over the watershed. Rainfall-runoff peaks are instead poorly reproduced by the lumped model, which assumes homogeneous rainfall over the entire watershed. Previous studies have shown and discussed that reliable results can sometimes be achieved more easily with lumped models depending on the question being asked [e.g., Jakeman and Hornberger, 1993].

[52] This study highlights that processes driven by meteorological forcing that vary significantly in space (e.g., evaporation or soil moisture fields) ideally should be better captured through wireless sensor networks themselves. The required number of measuring points across the study area strictly depends on the nature of the processes under investigation and on the morphology of the study area. We showed that the adiabatic lapse rates vary in time and space according to the time of the day and the location aspect. Also, rainfall data collected at several locations within the study area exhibit spatial variability. In addition, the distance among the stations has to be of the same order of magnitude as the scale of the spatial variability.

[53] Acknowledgments. The authors would like to thank the many members of the Laboratory of Environmental Fluid Mechanics and Hydrology, EFLUM team from EPFL, Lausanne, for their collaborative work in setting up the field campaign and for helping in the site maintenance. The authors are also thankful to Sensorscope Sàrl for its support in radio communication and data management. Funding from Mobile Information Communication Systems (MICS), Swiss National Science Foundation, grant 200021-120238/1, Swiss Center for Scientific Computing, and the EU FP-7 grant Hydrosys are gratefully acknowledged. We appreciate the peer review comments, which helped improve the paper substantially, and the assistance of the Associate Editor, Reed Maxwell.

\section{References}

Anderson, E. A. (1968), Development and testing of snow pack energy balance equation, Water Resour. Res., 4, 19-38, doi:10.1029/WR004i $001 \mathrm{p} 00019$.

Anderson, E. A. (2006), Snow accumulation and ablation model-SNOW17, technical report, 61 pp., NOAA, Silver Spring, Md.

Anderton, S. P., S. M. White, and B. Alvera (2004), Evaluation of spatial variability in snow water equivalent for a high mountain catchment, Hydrol. Processes, 18, 435-453.

Arnaud, P., C. Bouvier, L. Cisneros, and R. Dominguez (2002), Influence of rainfall spatial variability on flood prediction, J. Hydrol., 260, $216-230$.

Atkinson, S. E., M. Sivapalan, R. A. Woods, and N. R. Viney (2003), Dominant physical controls on hourly flow predictions and the role of spatial variability: Mahurangi catchment, New Zealand, Adv. Water Resour., 26, 219-235.

Bales, R. C., N. Molotch, T. Painter, M. Dettinger, R. Rice, and J. Dozier (2006), Mountain hydrology of the western United States, Water Resour. Res., 42, W08432, doi:10.1029/2005WR004387.

Barnett, T. P., J. C. Adam, and D. P. Lettenmaier (2005), Potential impacts of a warming climate on water availability in snow-dominated regions, Nature, 438, 303-309.

Blöschl, G. (1991), The influence of uncertainty in air temperature and albedo on snowmelt, Nord. Hydrol., 22, 95-108.

Bocchiola, D., C. Mihalcea, G. Diolaiuti, B. Mosconi, C. Smiraglia, and R. Rosso (2010), Flow prediction in high altitude ungauged catchments: A case study in the Italian Alps (Pantano Basin, Adamello Group), Adv. Water Resour., 33, 1224-1234.

Braithwaite, R. J. (1981), On glacier energy balance, ablation, and air temperature, J. Glaciol., 27, 381-391.

Bronstert, A., and A. Bardossy (1999), The role of spatial variability of soil moisture for modelling surface runoff generation at the small catchment scale, Hydrol. Earth Syst. Sci., 3, 505-516.

Brutsaert, W. (1986), Catchment-scale evaporation and the atmospheric boundary-layer, Water Resour. Res., 22, S39-S45, doi:10.1029/ WR022i09Sp0039S.

Brutsaert, W., and J. Nieber (1977), Regionalized drought flow hydrographs from a mature glaciated plateau, Water Resour. Res., 13, 637-644, doi:10.1029/WR013i003p00637.

Carenzo, M., F. Pellicciotti, S. Rimkus, and P. Burlando (2009), Assessing the transferability and robustness of an enhanced temperature-index glacier-melt model, J. Glaciol., 55, 258-274.

Cazorzi, F., and G. DallaFontana (1996), Snowmelt modelling by combining air temperature and a distributed radiation index, J. Hydrol., 181, 169-187.

Christoph, M. (2008), Regime shift of snow days in Switzerland, Geophys. Res. Lett., 35, L12501, doi:10.1029/2008GL033998.

Coles, N. A., M. Sivapalan, J. E. Larsen, P. E. Linnet, and C. K. Fahrner (1997), Modelling runoff generation on small agricultural catchments: Can real world runoff responses be captured?, Hydrol. Processes, 11, 111-136. 
DeBeer, C. M., and J. W. Pomeroy (2010), Simulation of the snowmelt runoff contributing area in a small alpine basin, Hydrol. Earth Syst. Sci., 14, 1205-1219.

Dooge, J. C. I. (1973), Linear theory of hydrologic systems, Tech. Bull. 1468, 327 pp. Agric. Res. Serv., U.S. Dep. of Agric., Washington, D. C.

Ernst, M. D. (2004), Permutation methods: A basis for exact inference, Stat. Sci., 19, 676-685.

Flerchinger, G. N., D. Marks, M. L. Reba, Q. Yu, and M. S. Seyfried (2010), Surface fluxes and water balance of spatially varying vegetation within a small mountainous headwater catchment, Hydrol. Earth Syst. Sci., 14, 965-978.

Garen, D., and D. Marks (2001), Spatial fields of meteorological input data including forest canopy corrections for an energy budget snow simulation model, in Soil-Vegetation-Atmosphere Transfer Schemes and LargeScale Hydrological Models, edited by A. Dolman et al., IAHS Publ., 270, 349-353.

Gottlieb, L. (1980), Development and applications of a runoff model for snow-covered and glacierized basins, Nord. Hydrol., 11, 255-272.

Grayson, R. B., I. D. Moore, and T. A. McMahon (1992), Physically based hydrologic modeling: 2: Is the concept realistic?, Water Resour. Res., 28, 2659-2666, doi:10.1029/92WR01259.

Grayson, R. B., G. Böschl, A. Western, and T. McMahon (2002), Advances in the use of observed spatial patterns of catchment hydrological response, Adv. Water Resour., 25, 1313-1334.

Grünewald, T., M. Schirmer, R. Mott, and M. Lehning (2010), Spatial and temporal variability of snow depth and SWE in a small mountain catchment, Cryosphere Discuss., 4, 1-30.

Hock, R. (2003), Temperature index melt modelling in mountain areas, J. Hydrol., 282, 104-115.

Huwald, H., C. W. Higgins, M.-O. Boldi, E. Bou-Zeid, M. Lehning, and M. B. Parlange (2009), Albedo effect on radiative errors in air temperature measurements, Water Resour. Res., 45, W08431, doi:10.1029/2008WR007600.

Ingelrest, F., G. Barrenetxea, G. Schaefer, M. Vetterli, O. Couach, and M. B. Parlange (2010), Sensorscope: Application-specific sensor network for environmental monitoring, ACM Trans. Sens. Networks, 6 , doi: $10.1145 / 1689239.1689247$.

Jakeman, A., and G. Hornberger (1993), How much complexity is warranted in a rainfall-runoff model, Water Resour. Res., 29, 2637-2649, doi: 10.1029/93WR00877.

Kampf, S., and S. Burges (2007), A framework for classifying and comparing distributed hillslope and catchment hydrologic models, Water Resour. Res., 43, W05423, doi:10.1029/2006WR005370.

Kelleners, T. J., D. G. Chandler, J. P. McNamara, M. M. Gribb, and M. S Seyfried (2010), Modeling runoff generation on a small snow-dominated mountainous catchment, Vadose Zone J., 9, 517-527.

Klemes, V. (1990), The modelling of mountain hydrology, in Hydrology of Mountainous Areas, Proceedings of the Strbske Pleso Symposium 1990 edited by L. Molnar, IAHS Publ., 190, 29-43.

Kruskal, W., and W. Wallis (1952), Use of ranks in one-criterion variance analysis, J. Am. Stat. Assoc., 47, 583-621.

Kustas, W. P., A. Rango, and R. Uijlenhoet (1994), A simple energy budget algorithm for the snowmelt runoff model, Water Resour. Res., 30 , 1515-1527, doi:10.1029/94WR00152.

Kuusisto, E. (1980), On the values and variability of degree-day melting factors in Finland, Nord. Hydrol., 11, 235-242.

Loague, K., and R. Freeze (1985), A comparison of rainfall-runoff modeling techniques on small upland catchments, Water Resour. Res., 21, 229-248, doi:10.1029/WR021i002p00229.

Luce, C. H., D. G. Tarboton, and R. R. Cooley (1998), The influence of the spatial distribution of snow on basin-averaged snowmelt, Hydrol. Processes, 12, 1671-1683.

Lundquist, J. D., J. R. Minder, P. J. Neiman, and E. Sukovich (2010), Relationships between barrier jet heights, orographic precipitation gradients, and streamflow in the northern Sierra Nevada, J. Hydrometeorol., 11, 1141-1156.

Mandapaka, P., W. F. Krajewski, R. Mantilla, and V. Gupta (2009), Dissecting the effect of rainfall variability on the statistical structure of peak flow, Adv. Water Resour., 32, 1508-1525.

Nadeau, D. F., W. Brutsaert, M. B. Parlange, E. Bou-Zeid, G. Barrenetxea, O. Couach, M.-O. Boldi, J. S. Selker, and M. Vetterli (2009), Estimation of urban sensible heat flux using a dense wireless network of observations, Environ. Fluid Mech., 9, 635-653.

Niemczynowicz, J. (1991), On storm movement and its applications, Atmos. Res., 27, 109-127.

Nolin, A. W., J. Phillippe, A. Jefferson, and S. L. Lewis (2010), Presentday and future contributions of glacier runoff to summertime flows in a
Pacific northwest watershed: Implications for water resources, Water Resour. Res., 46, W12509, doi:10.1029/2009WR008968.

Obled, C., J. Wendling, and K. Beven (1994), The sensitivity of hydrological models to spatial rainfall patterns: An evaluation using observed data, J. Hydrol., 159, 305-333.

Ohmura, A. (2001), Physical basis for the temperature-based melt-index method, J. Appl. Meteorol., 40, 753-761.

Painter, T. H., K. Rittger, C. McKenzie, P. Slaughter, R. E. Davis, and J. Dozier (2009), Retrieval of subpixel snow covered area, grain size, and albedo from MODIS, Remote Sens. Environ., 113, 868-879.

Parlange, M. B., W. E. Eichinger, and J. D. Albertson (1995), Regionalscale evaporation and the atmospheric boundary-layer, Rev. Geophys. 33,99-124, doi:10.1029/94RG03112.

Pomeroy, J., A. Rowlands, J. Hardi, T. Link, D. Marks, R. Essery, J. Sicart, and C. Ellis (2008), Spatial variability of shortwave irradiance for snowmelt in forecasts, J. Hydrometeorol., 9, 1482-1490.

Porporato, A., and L. Ridolfi (2003), Detecting determinism and nonlinearity in riverflow time series, Hydrol. Sci. J., 48, 763-780.

Redaño, A., and J. Lorente (1993), Modelling the spatial and temporal distribution of rainfall intensity at local scale, Theor. Appl. Climatol., 47, 25-32.

Rinaldo, A., A. Marani, and R. Rigon (1991), Geomorphological dispersion, Water Resour. Res., 27, 513-525, doi:10.1029/90WR02501.

Robeson, S. (1995), Resample of network-induced variability in estimates of terrestrial air temperature change, Clim. Change, 29, 213-229.

Schaefli, B., B. Hingray, M. Niggli, and A. Musy (2005), A conceptual glacio-hydrological model for high mountainous catchments, Hydrol. Earth Syst. Sci., 9, 95-109.

Schaefli, B., B. Hingray, and A. Musy (2007), Climate change and hydropower production in the Swiss Alps: Quantification of potential impacts and related modelling uncertainties, Hydrol. Earth Syst. Sci., 11 , 1191-1205.

Settin, T., G. Botter, I. Rodriguez-Iturbe, and A. Rinaldo (2007), Numerical studies on soil moisture distributions in heterogeneous catchments, Water Resour. Res., 43, W05425, doi:10.1029/2006WR005737.

Seyfried, M. S., and B. P. Wilcox (1995), Scale and the nature of spatial variability: Field examples having implications for hydrologic modeling, Water Resour. Res., 31, 173-184, doi:10.1029/94WR02025.

Shah, S., P. O’Connel, and J. R. M. Hosking (1996), Modelling the effects of spatial variability in rainfall on catchment response. 2: Experiments with distributed and lumped models, J. Hydrol., 175, 89-111.

Shea, J. M., and R. D. Moore (2010), Prediction of spatially distributed regional-scale fields of air temperature and vapor pressure over mountain glaciers, J. Geophys. Res., 115, D23107, doi:10.1029/2010JD 014351

Sicart, J. E., R. Hock, and D. Six (2008), Glacier melt, air temperature, and energy balance in different climates: The Bolivian tropics, the French Alps, and northern Sweden, J. Geophys. Res., 113, D24113, doi: 10.1029/2008JD010406.

Simoni, S., F. Zanotti, G. Bertoldi, and R. Rigon (2008), Modelling the probability of occurrence of shallow landslides and channelized debris flows using GEOtop-FS, Hydrol. Processes, 22, 532-545.

Singh, P., N. Kumar, and M. Arora (2000), Degree-day factors for snow and ice for Dokriani glacier, Garhwal Himalayas, J. Hydrol., $235,1-11$

Sivapalan, M. (2003), Prediction in ungauged basins: A grand challenge for theoretical hydrology, Hydrol. Processes, 17, 3163-3170.

Smith, J. A., M. L. Baeck, J. E. Morrison, and P. Sturdevant-Rees (2000), Catastrophic rainfall and flooding in Texas, J. Hydrometeorol., $1,5-25$

Smith, J. A., E. Hui, M. Steiner, M. L. Baeck, W. F. Krajewski, and A. A Ntelekos (2009), Variability of rainfall rate and raindrop size distributions in heavy rain, Water Resour. Res., 45, W04430, doi:10.1029/ 2008WR006840.

Stagnitti, F., J. Y. Parlange, T. S. Steenhuis, M. B. Parlange, and C. W. Rose (1992), A mathematical-model of hillslope and watershed discharge, Water Resour. Res., 28, 2111-2122, doi:10.1029/92WR00705.

Syed, K., D. Goodrich, D. Myers, and S. Sorooshian (2003), Spatial characteristics of thunderstorm rainfall fields and their relation to runoff, $J$. Hydrol., 271, 1-21.

Szilagyi, J., and M. B. Parlange (1999), A geomorphology-based semidistributed watershed model, Adv. Water Resour., 23, 177-187.

Szilagyi, J., M. B. Parlange, and J. D. Albertson (1998), Recession flow analysis for aquifer parameter determination, Water Resour. Res., 34 1851-1857, doi:10.1029/98WR01009. 
Tromp-van Meerveld, H. J., and J. J. McDonnell (2006), Threshold relations in subsurface stormflow: 2. The fill and spill hypothesis, Water Resour. Res., 42, W02411, doi:10.1029/2004WR003800.

Trubilowicz, J., K. Cai, and M. Weiler (2009), Viability of motes for hydrological measurement, Water Resour. Res., 45, W00D22, doi:10.1029/ 2008WR007046.

Tyler, S. W., S. A. Burak, J. P. Mcnamara, A. Lamontagne, J. S. Selker, and J. Dozier (2008), Spatially distributed temperatures at the base of two mountain snowpacks measured with fiber-optic sensors, J. Glaciol., 54, 673-679.

Vico, G., and A. Porporato (2009), Probabilistic description of topographic slope and aspect, J. Geophys. Res., 114, F01011, doi:10.1029/2008 JF001038.

Whiteman, D. C. (2000), Mountain Meteorology: Fundamentals and Applications, 355 pp., Oxford Univ. Press, New York.

Zecharias, Y., and W. Brutsaert (1988), Recession characteristics of groundwater outflow and base-flow from mountainous watersheds, Water Resour. Res., 24, 1651-1658, doi:10.1029/WR024i010p01651.

Zehe, E., T. Graeff, M. Morgner, A. Bauer, and A. Bronstert (2010), Plot and field scale soil moisture dynamics and subsurface wetness control on runoff generation in a headwater in the Ore mountains, Hydrol. Earth Syst. Sci., 14, 873-889.

Zuzel, J. F., and L. M. Cox (1975), Relative importance of meteorological variables in snowmelt, Water Resour. Res., 11, 174-176, doi:10.1029/ WR011i001p00174.

G. Barrenetxea, F. Ingelrest, and M. Vetterli, School of Computer and Communication Sciences, École Polytechnique Fédérale de Lausanne, EPFL Station 14, CH-1015 Lausanne, Switzerland.

M. Diebold, D. F. Nadeau, M. B. Parlange, and S. Simoni, School of Architecture, Civil and Environmental Engineering, École Polytechnique Fédérale de Lausanne, EPFL Station 2, CH-1015 Lausanne, Switzerland. (Marc.Parlange@epfl.ch)

S. Padoan, Dipartimento di Ingegneria dell'informazione e metodi matematici, Università degli studi di Bergamo, viale Marconi 5, I-24044 Dalmine, Italy.

A. Porporato, Department of Civil and Environmental Engineering, Duke University, 121 Hudson Hall, Durham, NC 27708-0287, USA. 